Int. J. Odontostomat., 10(2):333-341, 2016.

\title{
M/F Changes after T-loop Upper Horizontal Bending in Segmented Arch Mechanics
}

\author{
Cambios en Relación M/F después del Doblaje Horizontal Superior \\ en Ansas en $\mathrm{T}$ para Mecánicas de Arco Segmentado
}

Wilson A. Muñoz-Rendón; ; Yesid-de-Jesús Montoya-Goez"* \& David F. Gómez-Gil

MUÑOZ-RENDÓN, W. A.; MONTOYA-GOEZ, Y. \& GÓMEZ-GIL, D. F. M/F changes after T-loop upper horizontal bending in segmented arch mechanics. Int. J. Odontostomat., 10(2):333-341, 2016.

ABSTRACT: $\beta$ Ti T-type loops are a frictionless, efficient alternative for extraction space closure. Changes in the upper horizontal portion of T-type loops to improve their mechanical behavior have been proposed, but differences in their biomechanical characteristics have not been well described. This stu dy analyzed the biomechanical differences among three T-type loops with differential bends in their upper horizontal portion. Ninety loops $(0.017$ " $\mathrm{x} 0.025$ " $\beta \mathrm{Ti})$ were bent and randomly divided in 3 groups according to the form of their upper horizontal portion (T [straight], M [convex], and C-loops [concave]), to evaluate force characteristics up to $6 \mathrm{~mm}$ of activation. Stiffness, maximum horizontal loads, total loop moments, and moment-to-force ratios were obtained. Nonparametric statistical analyses were used to test differences among groups. M-loops demonstrated lower force than T- and C-loops, and higher total loop moment than T-loops. A significant increase in M-loop moment-to-force ratio compared with T- or C-loops was obtained. C- and T-loops did not demonstrate significant differences in moment-to-force ratio between them. The convex upper bend in M-loops produced an increased total loop moment compared with T-loops. M-loops demonstrated moment-to-force values slightly higher than translation values, while the other loops reported only controlled inclination values at $6 \mathrm{~mm}$ of activation. M-loops are ideal when a higher control of root movement is indicated since the beginning of dental retraction in segmented arch mechanics.

KEY WORDS: biomechanics, T-loops, beta titanium.

\section{INTRODUCTION}

Although low-friction orthodontics with/without passive self-ligating brackets has shown many benefits regarding treatment time, with a better, earlier, and easier root control than with conventional straight-wire systems (Tecco et al., 2007, 2009, 2011; Franchi et al., 2008; Heo \& Baek, 2011; Montasser et al., 2014), it also involves higher costs that convert this kind of approach inaccessible for low and middle class population in developing countries. Other alternatives should be explored to increase treatment effectiveness while reducing treatment time and costs.

In segmented arch orthodontics, elements delivering constant forces during long time spans are used to reduce treatment time in extraction cases. Closing loops in these settings allows the successive replication of these conditions, with minimum friction and high control of tooth movement (Burstone, 1982;
Kuhlberg \& Burstone, 1997; Nanda et al., 2005). Betatitanium ( $\beta$-Ti) (Goldberg \& Burstone 1979; Burstone \& Goldberg 1980), presents an unique combination of biocompatibility, resistance to corrosion, good formability, low stiffness, and adequate spring back with low permanent deformation, which are characteristics of ideal closing loop arches (Kapila \& Sachdeva, 1989; Juvvadi et al., 2010; Insabralde et al., 2014). A controlled inclination movement -instead of translation (Burstone) is applied from initial stages of space closure in such cases (Martins et al., 2009).

$\beta$-Ti T-type loops produce controlled orthodontic tooth movements in a time-efficient way (Gurgel et al., 2001), through the delivery of determined force systems that facilitate individualized or en-masse retraction (Insabralde et al.; Felemban et al., 2013). However, a significant decrease of force after $3 \mathrm{~mm}$ of deactivation

*Department of Integrated Basic Studies, College of Dentistry, Universidad de Antioquia, Medellín, Colombia.

"Biomaterials Laboratory, Biomedical Engineering Program, EIA-CES University Consortium, Medellín, Colombia. 
is regularly found in clinical settings (Menghi et al., 1999; Viecilli, 2006; Almeida et al., 2016). In chosen cases (bialveolar dental protrusion, bimaxillary protrusion), en-masse retraction using $\beta$ Ti-Mo T-type loops combined with dentoalveolar or osseous anchorage are one of the best time-efficient alternatives for dental movement (Burstone; Kuhlberg \& Burstone; Braun et al., 1997; Kuhlberg \& Priebe, 2003; Nanda et al., 2005; Felemban et al.).

With a correct selection of T-type loop, dental movement would be more accurate, minimizing treatment time and costs (Setiawan et al., 2011). Several studies have tried to modify the moment-toforce ratio $(\mathrm{M} / \mathrm{F})$ by changing either the position of the T-loop or its pre-activation bends, and have found that modifying loop height by applying a concave or convex bend in the upper portion of T-loops could affect the stiffness, force delivery and $M / F$ ratio, due to the effect these vertical changes have in the resulting dental movement (Hoenigl et al., 1995; Kuhlberg \& Burstone; Chen et al., 2000; Thiesen et al., 2005). Such changes can be performed in a rapid and standard fashion adding an extra convex bend in the superior portion of the T-loop (Uribe \& Nanda, 2003; Nanda), creating a $\mathrm{M} / \mathrm{F}$ differential that would change the amount of dental inclination at will (Nanda). However, no data is available on the biomechanical differences of such bending changes on forces, moments, and M/F ratios produced by this approach.

This in-vitro study wanted to determine if an upper convex bending in $\beta \mathrm{Ti}\left(\mathrm{TMA}^{\circledR}\right)$ T-type loops would increase its $\mathrm{M} / \mathrm{F}$ ratio, under laboratory conditions that control modifying factors in loop design (such as interbracket span, bracket type, wire size, and pre-activation).
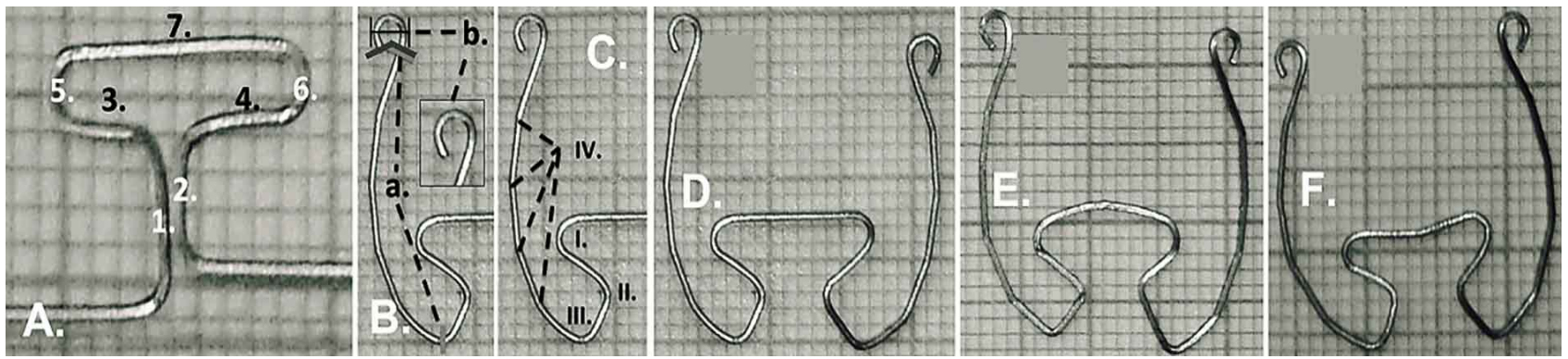

Fig. 1. Bending technique used in the $\beta$ Ti T-type loop groups. A) Internal T-type loop configuration: 1. 5-mm vertical segment, 2. 4-mm vertical segment, 3. and 4. 5-mm lower horizontal segment, 5. and 6. 2-mm curved segment, and 7. 10-mm upper horizontal segment; B) External T-type loop configuration: a. 20-mm curvilinear segment, b. 5-mm circular hooks for the attachment of the T-type loop to the testing machine; C) Preactivation bends. I. Opening preactivation bend in the curvature of the T-type loop, Closing preactivation bends at II. the union of lower horizontal and vertical components of the T-type loop, and at III. where the a and b segments start, and IV. 4 small curvilinear bends at the a and b segments to complete the 125 $\%$ preactivation set-up; D) T-loop (no bend); E) M-loop (1 mm convex bend); F) C-loop (1 mm concave bend). Each T-loop design corresponded with differences in bending of the upper horizontal segment. 


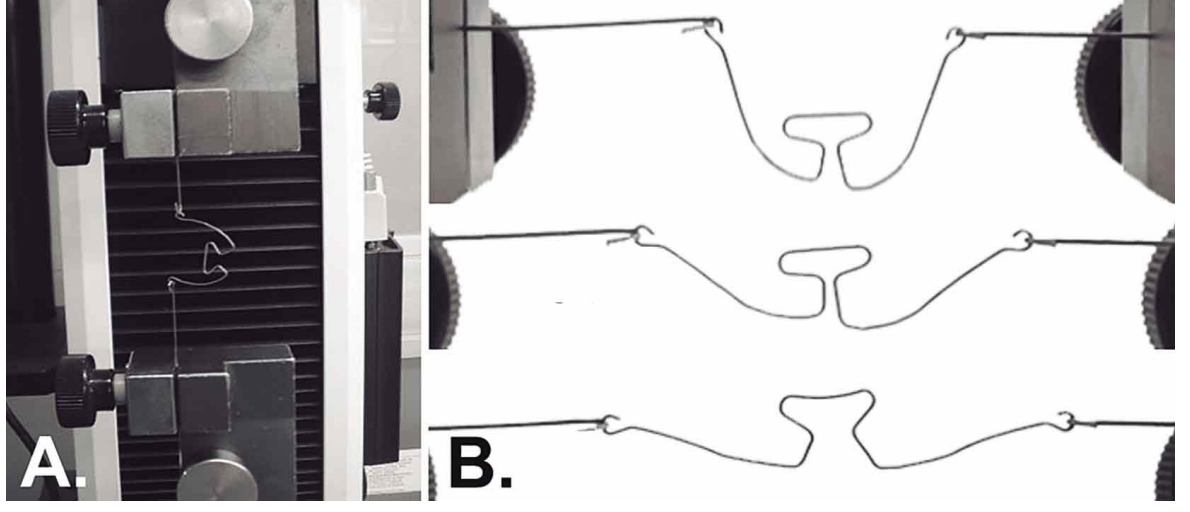

Fig. 2. Universal Testing Machine Set-Up used in the present study. A) T-type loop in position to perform the loading-unloading axial test; B) different stages of T-type loop activation. The activation was measured from the neutral T-type loop position onwards.

Table I. Normality Test.

\begin{tabular}{lcccc}
\hline & \multirow{2}{*}{ Researcher } & \multicolumn{3}{c}{ Shapiro-Wilk } \\
\cline { 3 - 5 } & & Stat. & Df & Sig. \\
\hline \multirow{2}{*}{ Stiffness } & 1 & 0.850 & 21 & 0.004 \\
& 2 & 0.845 & 39 & 0.000 \\
\hline \multirow{2}{*}{ Axial load } & 1 & 0.835 & 21 & 0.002 \\
& 2 & 0.795 & 39 & 0.000 \\
\hline
\end{tabular}

$p<0.05=* ; p<0.01=* * ; p<0.001=* * *$

Non-parametric statistical tests were used after defining that the sample was not normally distributed (Table I). A double-blinded MannWhitney $U$ test was no significant for force and stiffness at $6 \mathrm{~mm}$ of activation between and within researchers $(p>0.05)$ (Table II). Descriptive statistics and non-parametric tests for independent samples were used.

Table II. Error of the method.

\begin{tabular}{lcc} 
& Mann-Whitney U & Asymp. Sig. \\
\hline Stiffness & 389.5 & N.S. \\
Axial load & 392.0 & N.S. \\
\hline
\end{tabular}

\section{RESULTS}

All loop designs followed the linear elastic range behavior of an alloy during its range of motion. Due to this, the stiffness slope, axial maximum load values (force), and total moment at $6 \mathrm{~mm}$ of activation were used to describe their mechanical characteristics. The effect of upper curved bending on force production of T-type TMA loops at $6 \mathrm{~mm}$ of activation is shown in Table III. Kruskal-Wallis test demonstrated differences for applied force $(p<0.01)$ and stiffness ( $p<0.001)$ among groups. Mann-Whitney tests found that M-loops compared with T-loops had significantly lower applied force (M: $108.97 \pm 9.51 \mathrm{~g}$; $\mathrm{T}$ : $114.92 \pm 10.10 \mathrm{~g} ; \mathrm{p}<0.05)$ and lower stiffness (M: $11.61 \pm 1.29 \mathrm{~g} / \mathrm{mm}$; T: $12.64 \pm 1.44 \mathrm{~g} / \mathrm{mm} ; \mathrm{p}<0.01)$. M-type loops also produced significant lower force (M: $108.97 \pm 9.51 \quad \mathrm{~g} ; \mathrm{C}$ : $118.15 \pm 10.04 \mathrm{~g} ; \mathrm{p} \leq 0.001)$ and stiffness (M: 11.61 1.29 $\mathrm{g} / \mathrm{mm}$; C: $13.35 \pm 1.37 \mathrm{~g} / \mathrm{mm}$; $\mathrm{p}<0.001)$ than C-type loops. The effect of upper curved bending on total moment production is shown in Table IV. Kruskal-Wallis test demonstrated differences for total moment $(p<0.05)$ among groups. MannWhitney tests found that Mloops compared with T-loops had significantly higher total moment (M: 1031.00 \pm 89.12 $\mathrm{g} / \mathrm{mm}$; T: $967.16 \pm 84.71 \mathrm{~g} /$ $\mathrm{mm} ; \mathrm{p}<0.05$ ) at $6 \mathrm{~mm}$ of activation. When compared with C-type loops, M-type loops failed to demonstrate differences in moment ( $\mathrm{M}$ : $1031.00 \pm 89.12 \mathrm{~g} / \mathrm{mm}$; C:

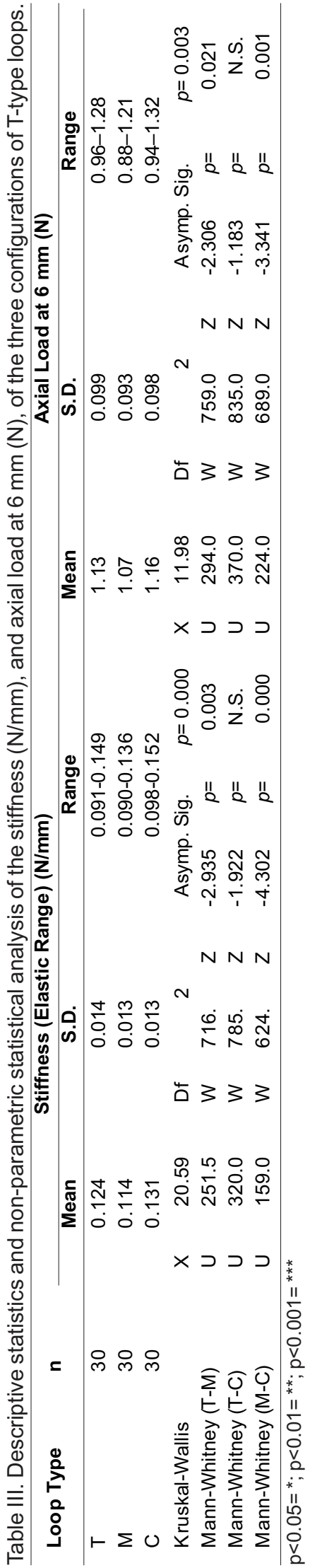


MUÑOZ-RENDÓN, W. A.; MONTOYA-GOEZ, Y. \& GÓMEZ-GIL, D. F. M/F changes after T-loop upper horizontal bending in segmented arch mechanics. Int. J. Odontostomat., 10(2):333-341, 2016.

Table IV. Descriptive statistics and non-parametric statistical analysis of total moment (N/mm) and M/F ratio for the three Ttype loop configurations.

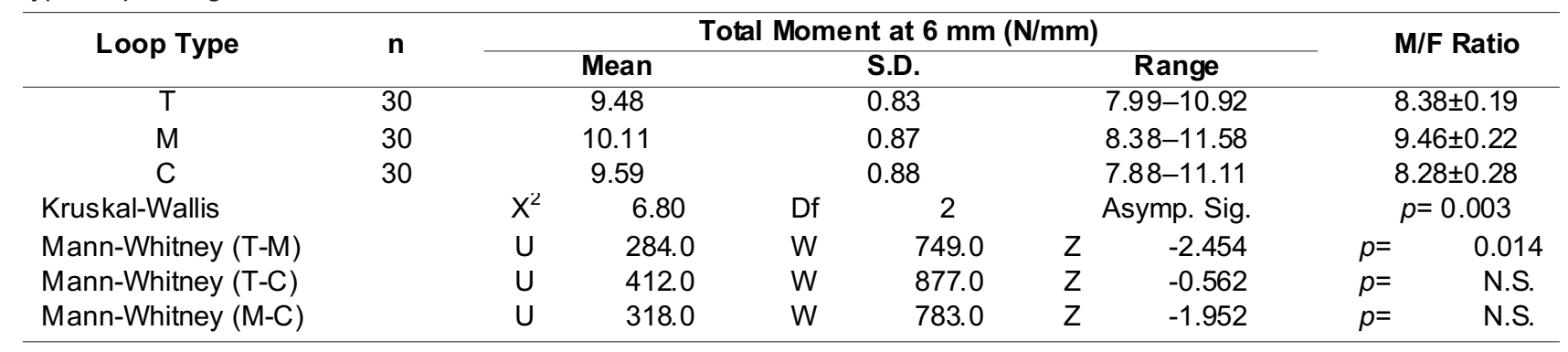

$978.30 \pm 90.11 \mathrm{~g} / \mathrm{mm} ; \mathrm{p}>0.05)$. A translational $\mathrm{M} / \mathrm{F}$ ratio was produced by M-loops (9.46 $\pm 0.94: 1)$, followed by lower and similar controlled inclination values for T(8.41 $\pm 0.84: 1)$ and C-type loops (8.28 $\pm 0.90: 1)$.

\section{DISCUSSION}

This in-vitro trial results demonstrate the positive effect of adding vertical pre-activation in the horizontal upper portion of the T-type loop to modify significantly either its $M / F$ ratio or force in segmented arch mechanics. M-type loops had lower values for stiffness and axial load at $6 \mathrm{~mm}$ of activation than T- or C-type loops, and demonstrated higher values of total moment than T-type loops.

Analytical relations among spring characteristics, design, dimension, and activation distance in a given retraction loop must be considered to fully understand its biomechanical behavior (Setiawan et al.). Several reports analyzed the effects of different wire crosssections, different pre-activation settings (symmetric arm activation vs. symmetric moments), and different IBD's on T-loops, either experimentally (Burstone; Manhartsberger et al., 1989; Kuhlberg \& Burstone; Rose et al., 2009; Setiawan et al.; Caldas et al., 2011a, 2011b), or clinically (Martins et al.; Keng et al., 2012; Xia et al., 2013; Li et al., 2014).

Burstone reported for 0.017 "x0.025" $\beta$ Ti T-loops force values of $281.8 \pm 5.1 \mathrm{~g}$, moment a of $2243.8 \pm 24.5$ $\mathrm{g} / \mathrm{mm}$ (M/F: 8.0:1), and moment b of $2261.6 \pm 18.3 \mathrm{~g}(\mathrm{~mm}$ (M/F: 8.0:1) at $6 \mathrm{~mm}$ of activation. Our lower values for force and moment in the T-type loop group, together with an increased $\mathrm{M} / \mathrm{F}$ ratio, were product of our higher IBD $(46 \mathrm{~mm})$ combined with the increase in arm preactivation. Our $\mathrm{M} / \mathrm{F}$ results for $\mathrm{M}$-loops were higher than for $\mathrm{T}$ - and $\mathrm{C}$-loops, indicating a biomechanical improvement obtained by the upper convex bending. Manhartsberger et al., analyzed the effect of reducing wire cross-section with concentrated vs. gradual curvature arm pre-activation for obtaining lower force and higher $\mathrm{M} / \mathrm{F}$ ratio, ideal for advanced periodontal conditions. Their force levels at $6 \mathrm{~mm}$ of activation for concentrated angulation were $302.8 \mathrm{~g}$ [no S.D.], with lower moment $\alpha(1,850.9 \mathrm{~g} / \mathrm{mm}$ [no S.D.] - M/F ratio: 6.1 [no S.D.]) and moment $\beta(1,858.1 \mathrm{~g} / \mathrm{mm}$ [no S.D.] M/F ratio: 6.1 [no S.D.]). The gradual curvature angulation group behold similarly (force: $300.9 \mathrm{~g}$ [no S.D.]; moment $\alpha: 2,493.1 \mathrm{~g} / \mathrm{mm}$ [no S.D.] - M/F ratio: 8.3 [no S.D.]; moment $\beta: 2,505.5 \mathrm{~g} / \mathrm{mm}$ [no S.D.] - M/ F ratio: 8.3 [no S.D.]). There was a change in the $\beta T i$ alloy composition that maybe accounts for the increase in force when compared with Burstone's original study, and our findings (IBD: $46 \mathrm{~mm}$ ). A minimum increase in gradual curvature angulation moments compared with acute angulation settings was found. Kuhlberg \& Burstone found that centered positioned T-loops with $\alpha$ and $\beta$ symmetrical gradual curvature angulation $\left(70^{\circ}\right)$, at an IBD of $23 \mathrm{~mm}$ and activated $6 \mathrm{~mm}$, produced $340.6 \pm 13.0 \mathrm{~g}$ of force, $1,929.9 \pm 60 \mathrm{~g} / \mathrm{mm}$ of moment $\alpha$ (M/F ratio: 5.7:1 [no S.D.]), and 2,264.7 $\pm 109,2 \mathrm{~g} / \mathrm{mm}$ of moment $\beta$ (M/F ratio: 6.6:1 [no S.D.]). For centered positioned T-loops with symmetric moments (gradual curvature angulation $73^{\circ} \alpha, 67^{\circ} \beta$ ), force was basically unchanged $(344.3 \pm 20.6 \mathrm{~g})$, moment $\alpha$ increased slightly $(2,079.2 \pm 73.2 \mathrm{~g}-\mathrm{M} / \mathrm{F}$ ratio: 6.0 [no S.D.]) and moment $\beta$ decreased $(2,126.8 \pm 176.8 \mathrm{~g}-\mathrm{M} / \mathrm{F}$ ratio: 6.2 [no S.D.]). Another major change in the composition of the $\beta \mathrm{Ti}$ alloy compared with Burstone's data was noted. Rose et al., compared force, moments, and M/ $F$ ratios produced by 0.017 " $x 0.025$ " $\beta$ Ti T-loops and 0.018 "x0.025" NiTi T-loops with $0^{\circ}, 15^{\circ}$, or $30^{\circ}$ of arm pre-activation on S.S. twin brackets of unknown slot size. NiTi T-loops produced a M/F ratio greater than 10:1 over a larger range than $\beta$ Ti T-loops. However, they used sectional mechanics (10 $\mathrm{mm}$ span), decreased pre-activation, and increased loop 
dimensions $(8.45 \times 10.45 \mathrm{~mm})$. Setiawan et al., described that $\mathrm{M}$-loops had both higher moments and forces than T-loops, statement that could not be proven analyzing their graphical data. In comparison, our Mloop data produced higher moments similar to this study, but lower forces due to our increased IBD. This controversy between theoretical and experimental analyses should be resolved next. Caldas et al. (2011a) compared the effect of concentrated and gradual preactivation in groups of ten 0.017 " $\times 0.025$ ", $6 \times 10 \mathrm{~mm} \beta \mathrm{Ti}$ T-loops at an IBD of $23 \mathrm{~mm}$ and $5 \mathrm{~mm}$ of activation. Curved pre-activations at $5 \mathrm{~mm}$ delivered significantly lower forces than concentrated bends, no differences in moments, and higher M/F ratios than in acute bending, similar to Manhartsberger's and our results. $\mathrm{M} / \mathrm{F}$ values for curved bended loops reached translation values $1 \mathrm{~mm}$ faster than acute ones. They did not address the effect of shorter distal vertical extension in their results. Caldas et al. (2011b) also evaluated the stress relaxation time effects on nine groups of ten concentrated curvature $0.017 " x 0.025 " \beta T i$ T-loops. They found a progressive decrease in force the first $24 \mathrm{~h}$, with a similar M/F ratio along the study. The issue of decreasing forces in $\beta \mathrm{Ti}$ T-loops with differential activation will be analyzed next.

Analyzing the clinical application of this approach, Martins et al., evaluated distal tipping of partially retracted maxillary and mandibular canines (with 0.022 " $\times 0.028$ " Lang -single wings- brackets) and mesial molar movement produced by 0.017 " $\times 0.025$ "

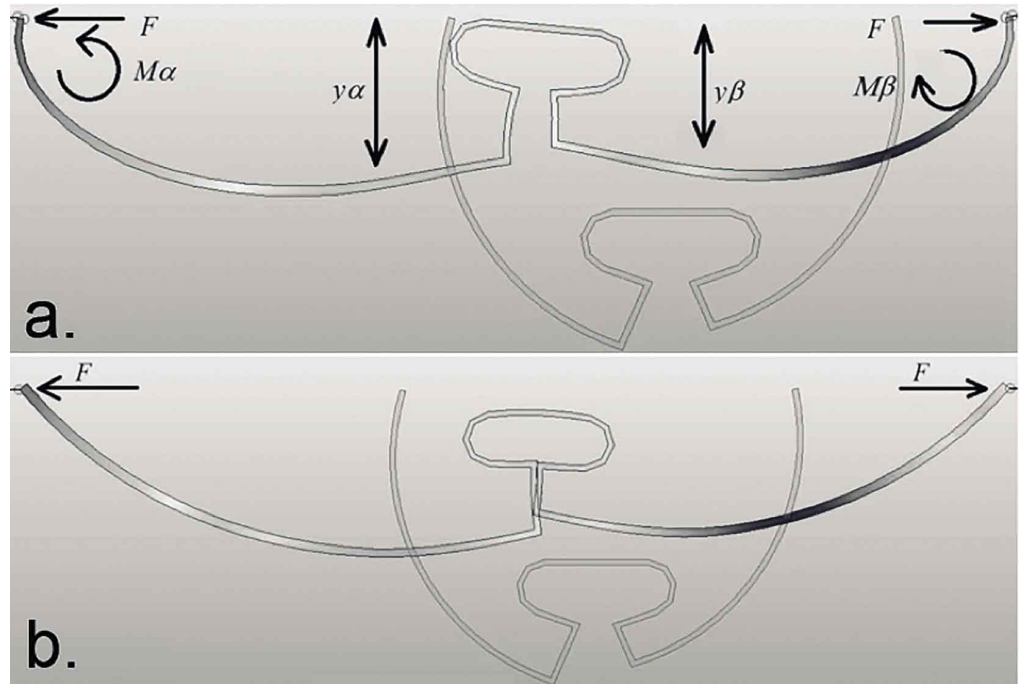

Fig. 3. Mechanical theoretical models of T-type loop action. A) Fixed constrain model; B) Free rotation end model used in this research. The three-point constrain model would be more accurate than the former two settings (diagram not shown). $\beta$ Ti T-loops with group $A$ anchorage $\left(45^{\circ}\right.$ gable bends) in eleven patients. They did not address the effect of having less tipping control using single vs. twin wings brackets, with wide free arch-to-bracket space $(0.005$ " open span) and smaller loop dimensions (6mm height). A clinical comparison using both bracket types and loop heights should be done. Keng et al., compared the rate of space closure and tooth angulation during maxillary canine retraction using either pre-activated $30^{\circ}$ gable bend $\beta$ Ti or NiTi T-loops on a S.S. base arch using a split-mouth randomization design. $\beta \mathrm{Ti}$ T-loops delivered canine retraction rates of $0.87 \pm 0.34 \mathrm{~mm} /$ month and tipping rates of $1.15 \pm 2.86$ degrees/month. The use of gable bend activation and S.S. base arches obscured the importance of using true segmental mechanics. Xia et al., in their individualized segmental $\beta T i$ T-loop retraction using FEM designed ideal templates in 9 patients, found a better, higher-but not ideal-control of root movement in translation and controlled tipping. Li et al., showed in their split-mouth clinical trial of 21 patients using segmental $\beta$ Ti T-loops bilaterally that a very well-controlled inclination load system did not guarantee consistent dental movement. Variations in T-type loop height that correspond with differences in anterior segment CR point must be consider to standardize $\mathrm{M} / \mathrm{F}$ according to root length. For minor changes in loop height, the conversion between conventional T-loops to M-loops would increase $M / F$ ratios and make controlled inclination more reliable. Performing a single bending in the superior portion of the T-loop with a system to register tooth movement similar to Li et al., for clinical settings would be ideal. The different modifications of the T-type loops give the clinician an easy mechanical tool in cases where either a translational movement (e.g. maxillary protrusion) or a controlled inclination (e.g. alveolar protrusion) is desired. A gingival loopforming bending could be applied to increase or decrease the $\mathrm{M} / \mathrm{F}$ in a straightforward way. M-type modification of the T-loop has proven to be valuable in clinical situations where a translational M/ $F$ ratio is desired.

Only hand-made $\beta$ Ti T-type loops were used. TMA ${ }^{\circledR}$ alloy (Ormco, Glendora, $\mathrm{CA})$, the $\beta$ Ti brand choosen for this study, was tested against other $\beta \mathrm{Ti}$ alloys by Insabralde et al. They reported an elastic modulus of $37.89 \pm 7.12 \mathrm{GPa}$, and a load/ deflection behavior $(1 \mathrm{~mm})$ in leveled 
brackets of $139.62 \pm 6.18 \mathrm{~g}$, situating the $\mathrm{TMA}^{\circledR}$ alloy in the middle of the evaluated $\beta$ Ti brands. It also demonstrated high value in deactivation, which decreased the duration time of tooth movement. Compared with $\mathrm{CNA}^{\circledR}$ wires, the $\mathrm{TMA}^{\circledR}$ clinical response demonstrated higher stiffness and less constant force delivery. As our research did not address the differences between original prefabricated $\mathrm{CNA}^{\circledR} \mathrm{M}$ loops and hand-made $\mathrm{TMA}^{\circledR} \mathrm{M}$-loops, a comparison between TMA ${ }^{\circledR}$ and other $\beta$ Ti brands will be consider next. TMA ${ }^{\circledR}$ alloys have demonstrated an increase in force, with a significant decrease in $\mathrm{M} / \mathrm{F}$ ratio (Burstone; Kuhlberg \& Burstone). However, the pre-activations settings have not changed accordingly. A new characterization of modified prefabricated $\beta \mathrm{Ti}$ T-type loops with all the before mentioned features should be done to make the standardization of the procedure more reliable and useful. In addition, a comparison of hand-made vs. pre-fabricated M-loops is important to clarify some important biomechanical aspects and issues.

The T-type loop behaves as a lineal elastic body, made on an homogeneous, isotropic material. Several approximations to the mechanical system exist. A threepoint constraint model is considered closer to the actual contact condition between the spring and bracket, using more precise measuring systems that are able to measure moments directly. This system will give us a better estimation of the behavior of the different Ttype loops (Chen et al., 2010). However, if this class of fixed settings was used, the system would require an extra set of strain gauges that would measure the internal mechanics between the bracket and the wire, whose moments depend on the fit of the wire inside the bracket and on the $\alpha$ and $\beta$ internal vertical dimensions of the T-loop. The fixed constraint model is simpler and commonly used. However, moments are still produced in the $\alpha$ and $\beta$ arms of the T-loop, that could not be measured with the settings in our lab (Fig. 3a). Our approximation consisted on a free rotation end model that only measured the applied force, with a mathematical estimation of the total moment generated inside the T-type loop. The strain gauges measured the applied force $(F)$ and the arm's displacements. Although our setup does not represent entirely the individual moments produced in the system, the reported moment corresponds to the total sum of $\alpha$ and $\beta$ moments produced by the loop with individual $\alpha$ and $\beta$ moments obtained by straightforward calculations. This approach quantified the total sum of moments inside the loop at any given activation and did not affect the force applied in any case (Fig. 3b). However, the neutral positions in any of the mechanical cases explained previously were only approximations from a mechanical ideal, with our settings underestimating the moment produced by the T-type loops more than in the other two conditions. This fact indicated that the results have to be interpreted with care. Other approaches such as the finite element method (FEM) analysis have also been used to evaluate T-loop positioning for canine retraction, without annotations about standard arm preactivation or T-type loop design (Tehranchi et al., 2013). Also, theoretical approaches (e.g. Castigliano's theorem) could be used in conjunction with FEM evaluation to the same end (Ungbhakorn et al., 2005). Structural analysis of canine and en-masse retraction using the three T-type loops designs from this research using FEM and other novel mechanical approaches (Mencattelli et al., 2015) will be considered next. We did not analyze long-term dental retraction patterns. The $M / F$ ratio from a loop increased with dental movement. In order to analyze these patterns specialized computer evaluation or FEM analysis of dental movement should be performed (Viecilli; Kojima et al., 2007; Kojima \& Fukui, 2012). We consider that a new $\beta$ Ti T-type loop calibration for segmental and sectional mechanics is in order, due to the current underestimation of the force produced by the different batches of $\beta \mathrm{Ti}$ that increase force and decrease $\mathrm{M} / \mathrm{F}$ ratio, regardless of activation settings and brands. Also, a comparison of T-loop software vs. mechanical testing should be considered next.

Conventional $\beta$ Ti-Mo T-loop has as its main problem that it has to be carefully built to obtain the desired force, even if the right batch of $\beta$ Ti-Mo is chosen. Other factors like differences in the degree of pre-activation across studies; the negative effect of forming T-type loops by manual bending instead of using prefabricated T-type loops; or inconsistencies regarding the measurement system used have to be taken into account. Our research was restricted by indirect and combined measurement of moments, rather than direct, individualized moment readings reported by Burstone's group, which had a universal testing machine set-up that allowed them the measurements of force and moments simultaneously (Solonche et al., 1977), or by Chen et al. (2010), which used a orthodontic force tester small enough to be used in clinical settings. The greater IBD in our study is not representative of a clinical situation. For this research we have no access to pre-bended T-loops, as was the case for all studies in Burstone's group. A comparison of manual vs. pre-fabricated T-loops is important to 
clarify this issue. Other alternatives for obtaining nonfrictional movement include the experimental use of NiTi T-type loops (Borauel et al., 1999; Almeida et al.). These wire modifications in non-frictional en-masse retraction mechanics should be the next step in its application in clinical orthodontics.

Burstone described several characteristics to exactly define any type of loops as follows: 1) The material of the wire used; 2) The cross-section of the wire; 3 ) The loop design (including: a. type of bending, b. internal and external pre-activation settings, c. degree of pre-activation symmetry, and d. eccentricity of the loop); 4) The target IBD; and 5) The activation applied. The M-loop used in this research employed an internal loop modification of the pre-activation bending that achieved a translational moment-to-force ratio at $6 \mathrm{~mm}$ of activation in a 46 IBD setting. Additional research would be needed to fully describe the M-loop behavior in IBD closer to clinical situations, as this conformational change in the gingival portion of the T-type loop would have a significant biomechanical impact on dental movement, as shown by the results of the present research.

MUÑOZ-RENDÓN, W. A.; MONTOYA-GOEZ, Y. \& GÓMEZ-GIL, D. F. Cambios en relación M/F después del doblaje horizontal superior en ansas en T para mecánicas de arco segmentado. Int. J. Odontostomat., 10(2):333-341, 2016.

RESUMEN: Las ansas tipo T de $\beta$ Ti son una alternativa eficiente para el cierre de espacios de extracción. Cambios en la porción horizontal de las ansas tipo T se han propuesto para mejorar su comportamiento mecánico, pero sus diferencias con relación a las características biomecánicas no han sido bien descritas. Este estudio analizo las diferencias biomecánicas entre tres ansas tipo $\mathrm{T}$ con dobleces diferenciales en su porción horizontal superior. Noventa ansas $(0,017$ "x0,025" $\beta$ Ti) fueron dobladas y divididas en tres grupos aleatoriamente, de acuerdo a la forma de su porción horizontal superior (ansas en T [recta], M [convexa], y C [cóncava]), para evaluar características de fuerza hasta $6 \mathrm{~mm}$ de activación. Rigidez, cargas horizontales máximas, momentos totales del ansa, y razones momento-fuerza fueron obtenidas. Análisis estadísticos no paramétricos se utilizaron para comprobar diferencias entre los grupos. Las ansas en M demostraron una menor fuerza que las ansas en T y C, y momentos totales del ansa mas altos que las ansas en T. Se obtuvo un incremento significativo en la razón momento-fuerza de las ansas en $\mathrm{M}$ comparado con las ansas en $\mathrm{T}$ o en $\mathrm{C}$. Las ansas en $\mathrm{C}$ y $\mathrm{T}$ no demostraron diferencias significativas en la razón momento-fuerza entre si. El doblez convexo superior en las ansas en $\mathrm{M}$ produjo un momento del ansa total incrementado comparado con las ansas en T. Las ansas en M mostraron valores de momento-fuerza ligeramente mas altos que los valores para translación, mientras que las otras ansas solo reportaron valores para inclinación controlada a $6 \mathrm{~mm}$ de activación. Las ansas en $\mathrm{M}$ son ideales cuando un control alto de movimiento radicular esta indicado desde en comienzo de la retracción dental en mecánicas de arco segmentado.

PALABRAS CLAVE: biomecánica; ansas en T; Beta titanio.

\section{REFERENCES}

Almeida, L.; Ribeiro, A.; Parsekian Martins, R.; Viecilli, R. \& Parsekian Martins, L. Nickel titanium T-loop wire dimensions for en masse retraction. Angle Orthod., 2016. In Press.

Bourauel, C.; Freudenreich, D.; Vollmer, D.; Kobe, D.; Drescher, D. \& Jäger, A. Simulation of orthodontic tooth movements. A comparison of numerical models. J. Orofac. Orthop., 60(2):136-51, 1999.

Braun, S.; Sjursen, R. C. Jr. \& Legan, H. L. On the management of extraction sites. Am. J. Orthod. Dentofacial Orthop., 112(6):645-55, 1997.

Burstone, C. J. \& Goldberg, A. J. Beta titanium: a new orthodontic alloy. Am. J. Orthod., 77(2):121-32, 1980.

Burstone, C. J. The segmented arch approach to space closure. Am. J. Orthod., 82(5):361-78, 1982.
Caldas, S. G.; Martins, R. P.; Galvão, M. R.; Vieira, C. I. \& Martins, L. P. Force system evaluation of symmetrical beta-titanium T-loop springs preactivated by curvature and concentrated bends. Am. J. Orthod. Dentofacial Orthop., 140(2):e53-8, 2011a.

Caldas, S. G.; Martins, R. P.; Viecilli, R. F.; Galvão, M. R. \& Martins, L. P. Effects of stress relaxation in beta-titanium orthodontic loops. Am. J. Orthod. Dentofacial Orthop., 140(2):e85-92, 2011b.

Chen, J.; Isikbay, S. C. \& Brizendine, E. J. Quantification of three-dimensional orthodontic force systems of T-loop archwires. Angle Orthod., 80(4):566-70, 2010.

Chen, J.; Markham, D. L. \& Katona, T. R. Effects of T-loop geometry on its forces and moments. Angle Orthod., 70(1):48-51, 2000. 
Felemban, N. H.; Al-Sulaimani, F. F.; Murshid, Z. A. \& Hassan, A. H. En masse retraction versus two-step retraction of anterior teeth in extraction treatment of bimaxillary protrusion. J. Orthod. Sci., 2(1):28-37, 2013.

Franchi, L.; Baccetti, T.; Camporesi, M. \& Barbato, E. Forces released during sliding mechanics with passive selfligating brackets or nonconventional elastomeric ligatures. Am. J. Orthod. Dentofacial Orthop., 133(1):8790, 2008.

Goldberg, J. \& Burstone, C. J. An evaluation of beta titanium alloys for use in orthodontic appliances. J. Dent. Res., 58(2):593-9, 1979.

Gurgel, J. A.; Kerr, S.; Powers, J. M. \& LeCrone, V. Forcedeflection properties of superelastic nickel-titanium archwires. Am. J. Orthod. Dentofacial Orthop., 120(4):378-82, 2001.

Heo, W. \& Baek, S. H. Friction properties according to vertical and horizontal tooth displacement and bracket type during initial leveling and alignment. Angle Orthod., 81(4):653-61, 2011.

Hoenigl, K. D.; Freudenthaler, J.; Marcotte, M. R. \& Bantleon, H. P. The centered T-loop--a new way of preactivation. Am. J. Orthod. Dentofacial Orthop., 108(2):149-53, 1995.

Insabralde, N. M.; Poletti, T.; Conti, A. C.; Oltramari-Navarro, P. V.; Lopes, M. B.; Flores-Mir, C. \& de Almeida, M. R. Comparison of mechanical properties of betatitanium wires between leveled and unleveled brackets: an in vitro study. Prog. Orthod., 15(1):42, 2014.

Juvvadi, S. R.; Kailasam, V.; Padmanabhan, S. \& Chitharanjan, A. B. Physical, mechanical, and flexural properties of 3 orthodontic wires: an in-vitro study. Am. J. Orthod. Dentofacial Orthop., 138(5):623-30, 2010.

Kapila, S. \& Sachdeva, R. Mechanical properties and clinical applications of orthodontic wires. Am. J. Orthod. Dentofacial Orthop., 96(2):100-9, 1989.

Keng, F. Y.; Quick, A. N.; Swain, M. V. \& Herbison, P. A comparison of space closure rates between preactivated nickel-titanium and titanium-molybdenum alloy T-loops: a randomized controlled clinical trial. Eur. J. Orthod., 34(1):33-8, 2012.

Kojima, Y. \& Fukui, H. Numerical simulations of canine retraction with T-loop springs based on the updated moment-to-force ratio. Eur. J. Orthod., 34(1):10-8, 2012.

Kojima, Y.; Mizuno, T.; Umemura, S. \& Fukui, H. A numerical simulation of orthodontic tooth movement produced by a canine retraction spring. Dent. Mater. J., 26(4):5617, 2007.
Kuhlberg, A. J. \& Burstone, C. J. T-loop position and anchorage control. Am. J. Orthod. Dentofacial Orthop., 112(1):12-8, 1997.

Kuhlberg, A. J. \& Priebe, D. Testing force systems and biomechanics--measured tooth movements from differential moment closing loops. Angle Orthod., 73(3):270-80, 2003.

Li, S.; Xia, Z.; Liu, S. S.; Eckert, G. \& Chen, J. Three-dimensional canine displacement patterns in response to translation and controlled tipping retraction strategies. Angle Orthod., 85(1):18-25, 2015.

Manhartsberger, C.; Morton, J. Y. \& Burstone, C. J. Space closure in adult patients using the segmented arch technique. Angle Orthod., 59(3):205-10, 1989.

Martins, R. P.; Buschang, P. H. \& Gandini, L. G. Jr. Group A Tloop for differential moment mechanics: an implant study. Am. J. Orthod. Dentofacial Orthop., 135(2):182-9, 2009.

Mencattelli, M; Donati, E.; Cultrone, M. \& Stefanini, C. Novel universal system for 3-dimensional orthodontic forcemoment measurements and its clinical use. Am. J. Orthod. Dentofacial Orthop., 148(1):174-83, 2015.

Menghi, C.; Planert, J. \& Melsen, B. 3-D experimental identification of force systems from orthodontic loops activated for first order corrections. Angle Orthod., 69(1):49-57, 1999.

Montasser, M. A.; El-Bialy, T.; Keilig, L.; Reimann, S.; Jäger, A. \& Bourauel, C. Force loss in archwire-guided tooth movement of conventional and self-ligating brackets. Eur. J. Orthod., 36(1):31-8, 2014.

Nanda, R. Dr. Ravindra Nanda on orthodontic mechanics. Interview by Robert G Keim. J. Clin. Orthod., 44(5):293302, 2010.

Nanda, R.; Kuhlberg, A. \& Uribe, F. Biomechanic Basis of Extraction Space Closure. In: Nanda, R. (Ed.). Biomechanics and Esthetics Strategies in Clinical Orthodontics. St. Louis, Elsevier Saunders, 2005.

Rose, D.; Quick, A.; Swain, M. \& Herbison, P. Moment-toforce characteristics of preactivated nickel-titanium and titanium-molybdenum alloy symmetrical T-loops. Am. J. Orthod. Dentofacial Orthop., 135(6):757-63, 2009.

Setiawan, R.; Idris, M. \& Prakasa, T. D. Mechanical behavior of various orthodontic retraction springs. I. T. B. J. Eng. Technol. Sci., 43(3):227-43, 2011.

Solonche, D. J.; Burstone, C. J. \& Vanderby, R. Jr. A device for determining the mechanical behavior of orthodontic appliances. I. E. E. E. Trans. Biomed. Eng., 24(6):538-9, 1977. 
Tecco, S.; Di lorio, D.; Cordasco, G.; Verrocchi, I. \& Festa, F. An in vitro investigation of the influence of self-ligating brackets, low friction ligatures, and archwire on frictional resistance. Eur. J. Orthod., 29(4):390-7, 2007.

Tecco, S.; Di lorio, D.; Nucera, R.; Di Bisceglie, B.; Cordasco, G. \& Festa, F. Evaluation of the friction of self-ligating and conventional bracket systems. Eur. J. Dent., 5(3):310-7, 2011.

Tecco, S.; Tetè, S. \& Festa, F. Friction between archwires of different sizes, cross-section and alloy and brackets ligated with low-friction or conventional ligatures. Angle Orthod., 79(1):111-6, 2009.

Tehranchi, A.; Farahani, M.; Ameli, N.; Mirhashemi, F. S. \& Ayazi, L. Displacement and stress distribution around maxillary canine root during sectional retraction in different T-loop positions: A finite element analysis. Int. J. Dent. Clin., 5(2):4-8, 2013.

Thiesen, G.; do Rego, M. V.; de Menezes, L. M. \& Shimizu, R. H. Force systems yielded by different designs of Tloop. Aust. Orthod. J., 21(2):103-10, 2005.

Ungbhakorn, V.; Ungbhakorn, V. \& Techalertpaisarn, P. Assessment of Castigliano's theorem on the analysis of closing loop for canine retraction by experiment and finite element method. Part I. Thammasat Int. J. Sci. Tech., 10(2):28-37, 2005.

Uribe, F. \& Nanda, R. Treatment of Class II, Division 2 malocclusion in adults: biomechanical considerations. J. Clin. Orthod., 37(11):599-606, 2003.

Viecilli, R. F. Self-corrective T-loop design for differential space closure. Am. J. Orthod. Dentofacial Orthop., 129(1):4853, 2006.

Xia, Z.; Chen, J.; Jiangc, F.; Li, S.; Viecilli, R. F. \& Liu, S. Y. Load system of segmental T-loops for canine retraction. Am. J. Orthod. Dentofacial Orthop., 144(4):548-56, 2013.
Correspondence to:

David F. Gómez-Gil

Department of Integrated Basic Studies

College of Dentistry

Universidad de Antioquia

Medellín

COLOMBIA

Email: df_gomez@yahoo.com

Received: 16-02-2016

Accepted: 14-04-2016 